\title{
A RANDOMIZED CONTROLLED TRIAL OF BALL AND SOCKET VS O-RING ATTACHMENTS FOR SINGLE IMPLANT-RETAINED MANDIBULAR OVERDENTURES. A STUDY OF CRESTAL BONE LOSS AND PATIENT SATISFACTION
}

\author{
Dina Bahgat El Talawy*
}

\begin{abstract}
Purpose: This short term randomized controlled trial aimed to evaluate crestal bone loss and patient satisfaction of ball and socket and O-ring attachments used to retain single implant-retained mandibular overdenture after one year.

Materials and methods: Twelve completely edentulous patients ( 6 men and 6 women) with maladaptive capacity of mandibular conventional denture received single implant in the midline of the mandible using standardized two stage surgical approach. Three months later, the patients were randomly assigned into two groups; Group 1 (control group); included six patients for whom the mandibular dentures were connected to the implant using ball and socket attachment. Group 2 (test group); included six patients for whom the mandibular dentures were connected to the implant using O/ring attachment. The peri-implant crestal bone loss was evaluated at mesial, distal, buccal and lingual aspects of each implant using cone beam computerized tomography made at baseline, 6 and 12 months later. Patient satisfaction was evaluated using questionnaire of visual Analogue Scales (VAS) six months after loading.
\end{abstract}

Results: The implant survival rate was $100 \%$ in both groups. Ball and socket attachment recorded significant higher crestal bone loss than O-ring attachment after 6 months $(p=.031)$ and 12 months $(\mathrm{p}=.021)$. Ball and socket attachment recorded significant higher patient satisfaction regarding retention $(\mathrm{p}=.027)$ and stability $(\mathrm{p}=.001)$ of mandibular overdenture, satisfaction with speech $(\mathrm{p}=.040)$, satisfaction with chewing $(\mathrm{p}=.015)$, satisfaction with occlusion of the prosthesis $(\mathrm{p}=.042)$, and satisfaction with quality of bolus $(\mathrm{p}=.031)$ than $\mathrm{O} /$ ring attachment.

Conclusion: O/ring attachment is recommended than ball and socket attachment for single implant mandibular overdentures in term of peri-implant bone preservation. However, ball and socket attachment was associated with significant higher patient satisfaction than $\mathrm{O} /$ ring attachment.

* Associate Professor, Removable Prosthodontic Department College of Oral and Dental Surgery, Misr University For Science and Technology, Giza Egypt. 


\section{INTRODUCTION}

The poor retention and stability of conventional complete denture may lead to an inability to masticate food, decrease in social contact, patient satisfaction and quality of life ${ }^{1}$. Although 2- implant-assisted mandibular overdentures has been considered the first treatment for edentulous patient as it was associated with increased retention and stability of the dentures, improved chewing efficiency, patient satisfaction and oral health-related quality of life ${ }^{2,3}$, single implant inserted in the symphysis of the mandible to retain overdentures is another simple treatment modality that gained popularity in the last two decades ${ }^{1,4-9}$. This treatment modality is less invasive, has reduced $\operatorname{cost}^{5}$, greatly improved retention and patient satisfaction of conventional denture $^{10}$ and is more feasible in developing countries due to financial limitations ${ }^{1}$. Moreover, it can be used with greater safety for geriatric patients (with compromised medical conditions) who had discomfort with their conventional denture ${ }^{6}$. In a recent systematic review and meta-analysis ${ }^{11}$, no significant difference in the implant survival rate between single implant overdentures in the two implant overdentures after 5 and 10-years was noted. The disadvantages of single implant overdentures include; 1) denture base deformation and fracture at midline due to stress concentration in the weak area of the denture base around the abutment ${ }^{5,12}$, $\left.{ }^{13}, 2\right)$ reduced retention and stability compared to 2- implant retained overdentures ${ }^{1}$, and 3 ) the ThreeDimensional prosthesis movement compared to two-implant assisted mandibular overdentures ${ }^{14}$.

The most commonly used attachments for single implant overdenture are ball, Locator or magnet attachments 9,15. Ball attachments are the simplest ones to use and provide high wear resistance, good stability, retention, and support especially for patients with narrow jaw anatomy ${ }^{16}$. Moreover, ball attachments offer better stability, bracing effect, and reduced costs when compared to shorter locator attachments ${ }^{17,18}$. Ball attachment provides varying degree of resiliency in both vertical and horizontal directions which depends on the design of the ball attachment ${ }^{19}$. Ball attachments have two types; 1) Dalbo attachment (Dalla-Bona); consisted of ball male in spherical shape and golden metal housing which is adjusted by gently bending the finger springs around the open end of the socket ${ }^{20}, 2$ ) O-ring attachment; consisted of titanium ball head and metal retaining ring that contain groove or undercut area that hold $\mathrm{O} /$ ring around the ball head. $\mathrm{O} /$ ring is an elastomeric material usually made of silicone $^{21}$.

Compared to 2-implant overdentures, single implant overdentures were found to produce higher stresses to the peri-implant bone ${ }^{22}$. The factors that may affect biomechanical stress distribution around the implants and the retention value of the prosthesis for single implant overdentures including; type of attachment and implant geometry and material ${ }^{23}$. Therefore, proper selection of the attachment type for single implant overdenture is an important factor as it may affect stress distribution at periimplant bone ${ }^{24}$, overdenture retention and patient satisfaction ${ }^{25}$.

An important criterion of the implant success is the assessment of crestal bone loss around the implants ${ }^{1}$. Also, patient reported outcomes are very useful in the success of overall overdenture treatment ${ }^{26,}$ 27. Among the most common patient reported outcomes are patient satisfaction and oral health-related quality of life ${ }^{7}$. The patient satisfaction in completely edentulous patients usually involves function and comfort outcomes such as satisfaction with retention and stability, phonetics, comfort, mastication, appearance and social activity which are evaluated using selfadministered questionnaires. ${ }^{7,28}$

Reviewing the literature, the clinical efficacy of single implant overdentures was reported in previous studies regarding high survival rate of 
the implants ${ }^{29}$, improvement of oral health-related quality of life ${ }^{10,30}$, acceptable marginal bone $\operatorname{loss}^{30}$, improved masticatory performance ${ }^{31}$ and maximum bite force, and acceptable incidence of prosthetic adjustments $^{32}$. Previous studies showed that single implant overdentures can significantly improve patient satisfaction compared to conventional mandibular dentures ${ }^{33,34}$. However, no studies were concerned with evaluation of marginal bone loss around implants and patient satisfaction with the ball and socket (Dalbo) and O-ring attachments. Therefore, the aim of the present randomized trial was to evaluate crestal bone loss and patient satisfaction of ball and socket and O-ring attachments used to retain single implant-retained mandibular overdenture after one year. The null hypothesis was that there will be no difference in the tested outcomes between the two attachments.

\section{MATERIALS AND METHODS}

\section{Patient cohort and study design}

Twelve completely edentulous patients ( 6 men and 6 women, mean age $=57.6 \pm 4.5$ years) with maladaptive capacity of mandibular conventional denture were recruited for this randomized trial from the outpatient clinic of Prosthodontic Department of College of Oral and Dental Surgery of Misr University for Science and Technology . All patients were unsatisfied with retention and stability of their mandibular overdentures. The inclusion criteria are; 1) complete maxillary and mandibular edentulism for at least one year with desire to replace mandibular overdenture with implantretained overdentures, 2) sufficient bone height and width in the symphysis of the mandible to receive implant of at least $9 \mathrm{~mm}$ in length and 3.7 in diameter as verified by preoperative diagnostic cone beam CT. 3) sufficient restorative space (at least $10 \mathrm{~mm}$ from the occlusal plane of the mandibular denture to the mucosa), 4) healthy mucosa without soft tissue abnormalities. Exclusion criteria include;
1) any systemic disease that affect osteointegration such as diabetes mellitus, and hyperparathyroidism, 2) diseases that may contraindicate implant surgery such as bleeding disorders, radiation to head and neck region, 3) bad habits such as bruxism and smoking, 4) patients under immunosuppressive or systemic biphosphate drugs, 5) neuromuscular or TMJ disorders, 6) uncooperative patients or patients who will be unable to attend the follow-up visits regularly. Each patient was provided with a copy of protocol and objectives of the research, and each patient was asked to sign an informed consent for participation. The study was conducted according to Helsinki guidelines for ethics in the present study and was approved by the college local ethical committee.

The existing dentures were carefully assisted for fitness, border extensions, aesthetics and occlusal relationships. If needed, new conventional maxillary and mandibular dentures were constructed using the bilateral occlusal balanced concept (using semi-anatomic teeth), with freedom in centric and eccentric occlusal contacts. Dentures were delivered to the participants, and they were instructed to wear the dentures for 30 days. This period was considered enough for functional adaptation and adjustment of the dentures if needed ${ }^{6}$. All patients received single implant in the midline of the mandible using standardized two stage surgical approach. Three months later, the patients were randomly assigned into two groups using computer generated numbers generated in Excel sheet (using RAND command) by independent observer. Each patient received a number. Randomization and allocation were performed to ensure equal gender distribution in each group. Group 1 (control group); included six patients ( 3 men and 3 women) for whom the mandibular dentures were connected to the implant using ball and socket attachment. Group 2 (test group); included six patients ( 3 men and 3 women) for whom the mandibular dentures were connected to the implant using $\mathrm{O} /$ ring attachment. 


\section{Surgical and prosthetic procedures}

The patient's existing mandibular denture was duplicated into heat cure clear acrylic resin to be used as a radiographic template. Gutta purcha radiopaque markers were attached at midline of the denture. Cone beam computerized tomography was performed to evaluate bone quantity and quality in this area, detect the proper implant length and diameter, evaluate alveolar bone inclination at midline and detect lingual concavities, and determine proximity to vital structures (lingual artery, submental artery and nerves and branches of incisive canals). The radiographic template was then converted to surgical template by attaching metal tubes at midline of the denture (at proposed implant position). A single implant (length ranged from $9-13 \mathrm{~mm}$, and width ranged from $3.7-4.2 \mathrm{~mm}$, Tiologic, Dentaurum, Germany) was inserted and the midline of the mandible using standardized submerged surgical approach by the same blind oral and maxillofacial surgeon. The conventional implant loading was performed as recommended by Cordioli, et al10. A limited crestal incision was performed in the midline area of the mandible, and minimal flap reflection was made to expose the alveolar crest of the ridge (fig. 1). If sharp alveolar crest or knife edge ridge exists, bone recontouring or flattening was performed using crestal osteotome to provide at least $1 \mathrm{~mm}$ of bone buccal and lingual

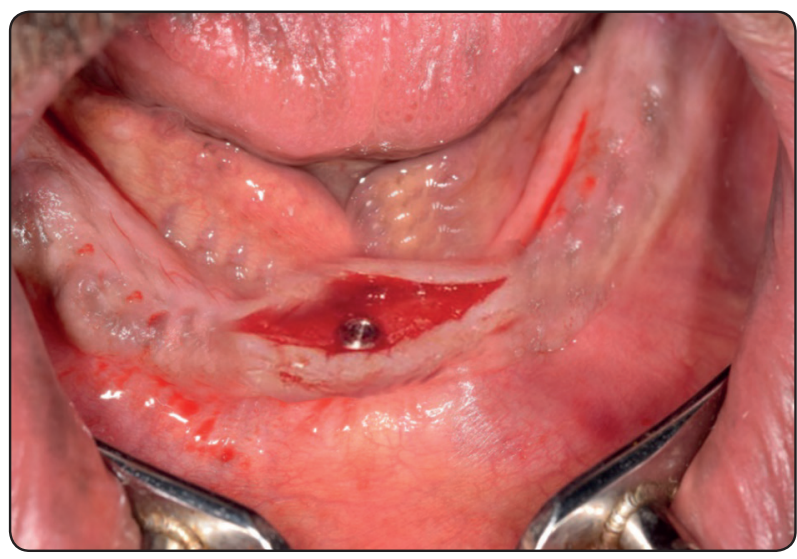

Fig. (1) Flap design to the implant. Implant osteotomy was performed using sequential drills of increasing diameters. If very dense bone exists, countersinking was performed using countersinking drills. After implant insertion the flap was closed using interrupted sutures (Vicryl, 0000).

The mandibular denture was relieved over the implant area and relined using a tissue conditioning liningmaterial(COEsoft,GCAmerica).Postoperative medications included antibiotics (Augmentin, 1gm, twice daily), mouthwash (chlorhexidine $0.2 \%, 3$ times daily), analgesics (Ibuprofen $400 \mathrm{mg}$ ) and anti-inflammatory medications (Alphintern, 3 times daily). All medications were continued for 7 days post surgically. The second stage surgery was performed three months after implant placement. Healing abutment connected to the implants and the denture base was relined over the healing abutment for two weeks, then soft liner was replaced by hard acrylic resin reline in the dental laboratory.

For both groups, ball abutments $($ size $=$ medium, gingival height $=3 \mathrm{~mm}$; ball diameter $=2.25 \mathrm{~mm}$, Tiologic, Dentaurum, Germany) were connected to the implant at $25 \mathrm{Ncm}$ torque. Plastic circular shim was snapped over ball abutment to reenter the metal housing of the ball vertically and prevent excess acrylic resin from entering the undercuts around the ball (fig. 2). Small circle rubber dam sheet was positioned around the ball abutments to prevent

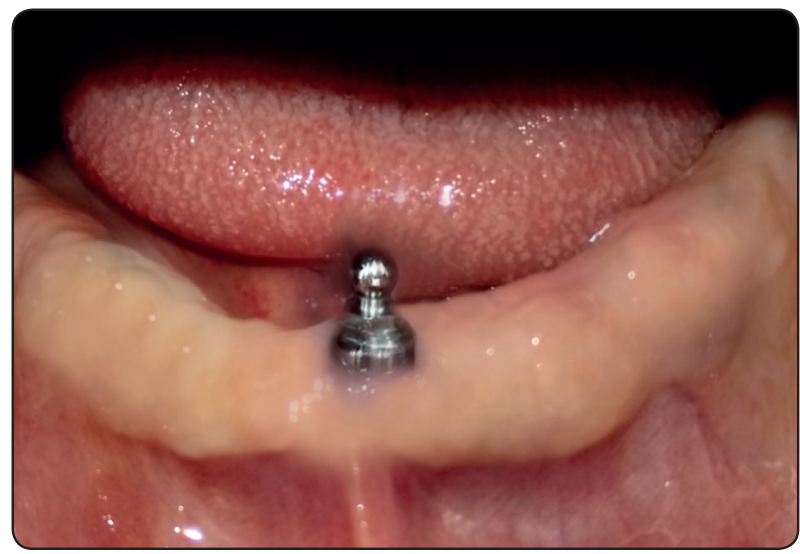

Fig. (2) Ball abutments screwed to the implant fixtures 
contact of acrylic resin with the abutments which may cause unwanted occlusal overloading of the implants.

The metal housing of the ball and socket attachment (control group) consisted of outer matrix that is attached to the fitting surface of the overdenture during the pick-up procedure, and the inner matrix (Unor Ecco Au / Pt standard, approx. $800 \mathrm{~g}$, Dentaurum, Germany) that is attached to the fitting surface of the outer matrix. The inner matrix has 4 lamellae to enable matrix activation if the retention is lost. The metal housing of $\mathrm{O} /$ ring attachment consisted of metal base that is attached to the fitting surface of the overdenture and inner interchangeable elastic rubber $\mathrm{O} /$ rings (Nitryl, Dentaurum, Germany) that is enclosed within undercut in the metal base. For both groups, the mandibular dentures, the metal housings were snapped over ball abutments, and the mandibular dentures were sufficiently relieved over the housing and preparation for pick-up procedure. Care must be taken to avoid contact of the metal housing to the acrylic resin of the dentures. Lingual vent holes were drilled in the lingual flange of overdenture to permit escape of excess acrylic resin. The metal housings were picked up to the fitting surface of the mandibular overdenture using self-cure acrylic resin while the patient holding the dentures in centric occlusion under moderate occlusal pressure. The dentures were removed, excess acrylic resin was removed and dentures were finished and polished (Fig. 3). Necessary occlusal adjustments were performed to ensure simultaneous and homogenous occlusal contact in centric and eccentric positions. No metal reinforcement of the denture bases was performed for both groups. The dentures were delivered to the participants, and oral hygiene instructions were given to the patients. Follow-up visits were scheduled to collect study outcomes. All prosthetic procedures were performed by the same prosthodontist who cannot be blinded.

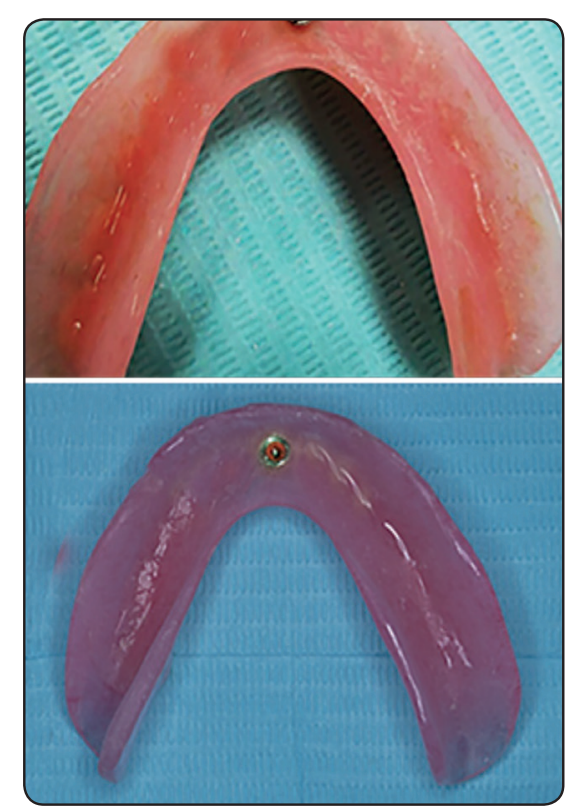

Fig. (3): A. Control group, metal socket attached to the fitting surface of the denture, B. Study group, O/ring attached to the fitting surface of the denture.

\section{Evaluation of study outcomes}

\section{Evaluation of crestal bone loss}

The peri-implant crestal bone loss was evaluated at mesial, distal, buccal and lingual aspects of each implant using cone beam computerized tomography (CBCT i-CAT device; Imaging Sciences Intl, Hatfield, USA) according to the procedure described by Elsyad et al ${ }^{35,36}$. Marginal bone height was evaluated at baseline (after loading), 6 and 12 months later. The scanning parameters were standardized for all participants (field of view [FOV], $8 \mathrm{~cm} 8 \mathrm{~cm}$; voxel size, $0.125 \mathrm{~mm} ; 120$ $\mathrm{kVp} ; 5 \mathrm{~mA}$; 23 Seconds ${ }^{37}$. The CBCT scans were downloaded on a compact disc for each participant. The software of the CBCT (OnDemand3DApp Software; CyberMed Inc) was used for measurement of marginal bone height. In the occlusal view window, the curvature tool was used to follow the crest of the alveolar ridges mesiodistallty at midline and to bisect the implant in the mesiodistal direction. The software reformates the images in panoramic window to allow evaluation of marginal 


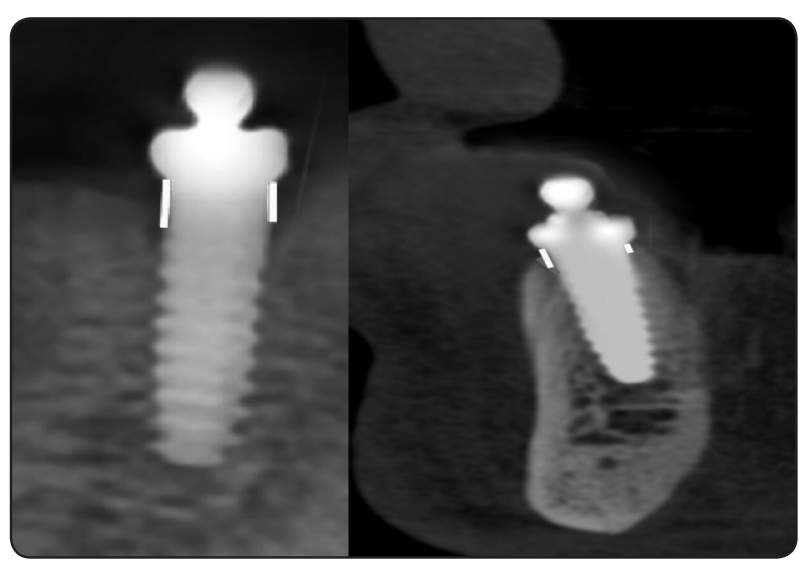

Fig. (4). Evaluation of marginal bone height, a) at mesial and distal surface of each implant in the panoramic images, b) at buccal and lingual surface of each implant in the cross-sectional images

bone height at mesial and distal surface of each implant (Fig.4a). In the occlusal view, the implant was bisected buccolingually to allow evaluation of marginal bone height at buccal and lingual implant surfaces in the cross-section window (Fig.4b). Marginal bone height was evaluated as a vertical distance (in $\mathrm{mm}$ ) from the implant platform to the first bone to implant contact $^{36}$. Crestal bone loss was calculated as the difference in marginal bone height recorded at visits (6 months and 12 months) from marginal bone height recorded at baseline (after loading). The crestal bone loss at mesial and distal, buccal and lingual surface of each implant was averaged for each implant and the mean was subjected to statistical analysis.

\section{Evaluation of patient satisfaction}

For both groups, patient satisfaction was evaluated using questionnaire of visual Analogue Scales (VAS) six months after loading. This questionnaire is valid and reliable tool for measuring patient satisfaction $^{38,39}$ and was given to the patients in Arabic version. The validity of the Arabic version was tested in previous studies ${ }^{27}, 40$. Each patient was asked to make a mark in a horizontal line (graduated from 0 to 100) to denote the level of his satisfaction with particular item. The items include; satisfaction with mandibular dentures regarding retention, stability, speech, socializing, embarrassment, handling, chewing, oral hygiene, occlusion, and quality of bolus (Fig. 5).

1) Retention: To what degree are you satisfied with the retention of your mandibular prosthesis?"

2) Speech: "To what degree are you satisfied with speech?

3) Socializing: To what degree are you satisfied with socializing?

4) Stability: To what degree are you satisfied with the stability of your mandibular prosthesis?

5) Embarrassment: Degree of embarrassment?

6) Handling: To what degree are you satisfied with handling

7) Ease of chewing: Degree of satisfaction with chewing?

8) Ease of cleaning : To what degree are you able to clean your mandibular prosthesis?

9) Occlusion: To what degree are you satisfied with the occlusion of your prosthesis?

10) Quality of bolus: Degree of satisfaction with quality of bolus before swallowing?

Fig. (5) Items included in the Visual Analogue Scales (VAS) questionnaire

\section{Statistical analysis}

The data was analyzed using the SPSS statistical package version 22 (SPSS Inc., Chicago, IL, USA). To detect the normal distribution of data, ShapiroWilk test was used. The data of crestal bone loss was parametric and presented by mean \pm standard deviation. The data of patient satisfaction was nonparametric and presented as median (minimummaximum). Comparison of crestal bone loss between groups was performed by student t-test and between observation times was performed by paired t-test. Comparison of patient satisfaction data between groups was performed using MannWhitney test. $\mathrm{P}$ is significant if $<0.05$ at confidence interval $95 \%$. 


\section{RESULTS}

All the patients attended the follow-up visits with dropouts. After 12 months of overdenture insertion, the implant survival rate was $100 \%$ in both groups. No implant failures occurred in both groups. Two patients in the ball and socket group had denture fractures at midline opposite to the attachment. The dentures were repaired and metal reinforcement skeleton was constructed around the attachment. No denture fractures occurred in the O-ring attachment group.

Comparison of crestal bone loss between ball and socket and O/ring attachments at 6 and 12 months after insertion is presented in table 1 . The mean crestal bone resorption after one year was $1.15 \pm .36 \mathrm{~mm}$ and $.86 \pm .23$ for ball and socket and $\mathrm{O} /$ ring attachments respectively. There was a significant difference in crestal bone loss between groups and between observation times. After six months of insertion, ball and socket attachment recorded significant higher crestal bone loss than O-ring attachment $(\mathrm{p}=.031)$. Also, after 12 months of insertion, ball and socket attachment recorded significant higher crestal bone loss than O-ring attachment $(\mathrm{p}=.021)$. Comparing observation times reveal that crestal bone loss after 12 months with significantly higher than bone loss after 6 months for both groups ( $\mathrm{p}=.001$ for ball and socket attachment, and $\mathrm{p}=.003$ for $\mathrm{O} /$ ring attachment).

TABLE (1) Comparison of crestal bone loss between ball and socket and $\mathrm{O} /$ ring attachments and between 6 and 12 months after insertion

\begin{tabular}{|c|c|c|c|c|c|}
\hline & \multicolumn{2}{|c|}{6 months after insertion } & \multicolumn{2}{|c|}{12 months after insertion } & \multirow{2}{*}{$\begin{array}{c}\text { Paired samples } t \text {-test } \\
\text { P value }\end{array}$} \\
\hline & Mean & St deviation & Mean & St deviation & \\
\hline Ball and socket & $.85 \mathrm{a}$ & .19 & $1.15 \mathrm{a}$ & .36 & $.001 *$ \\
\hline O/ring & $.54 \mathrm{~b}$ & .16 & $.86 \mathrm{~b}$ & .23 & $.003 *$ \\
\hline $\begin{array}{c}\text { Student t-test } \\
\text { P value }\end{array}$ & \multicolumn{2}{|c|}{$.031 *$} & \multicolumn{2}{|c|}{$.021 *$} & \\
\hline
\end{tabular}

*p is significant at $5 \%$

TABLE (2) Comparison of medians of patient satisfaction (VAS in $\mathrm{mm}$ ) for each question between ball and socket and $\mathrm{O} /$ ring attachments

\begin{tabular}{|c|c|c|c|c|}
\hline & & Ball and socket & O/ring & Mann- \\
\hline Question & & $\mathbf{M}(\mathbf{m i n}-\mathbf{m a x})$ & M(min-max $)$ & Whitney test \\
\hline 1 & Degree of satisfaction with retention of mandibular overdenture & $85(70-95)$ & $80(65-90)$ & $.027 *$ \\
\hline 2 & Degree of satisfaction with stability of mandibular overdenture & $90(75-95)$ & $78(60-85)$ & $.001 *$ \\
\hline 3 & Degree of satisfaction with speech & $82(78-95)$ & $74(70-85)$ & $.040 *$ \\
\hline 4 & Degree of satisfaction with socialization & $85(70-90)$ & $83(65-90)$ & .257 \\
\hline 5 & Degree of embarrassment & $70(50-80)$ & $73(55-83)$ & .124 \\
\hline 6 & Degree of satisfaction with handling of mandibular overdenture & $86(73-91)$ & $83(74-90)$ & .367 \\
\hline 7 & Degree of satisfaction with chewing & $91(79-95)$ & $82(71-92)$ & $.015 *$ \\
\hline 8 & Ability to clean the mandibular prosthesis & $91(75-95)$ & $90(77-94)$ & .654 \\
\hline 9 & Degree of satisfaction with occlusion of the prosthesis & $88(80-91)$ & $80(69-90)$ & $.042 *$ \\
\hline 10 & Degree of satisfaction with quality of bolus before swallowing & $84(73-89)$ & $77(70-84)$ & $.031 *$ \\
\hline
\end{tabular}

*p is significant at $5 \%$ 
Comparison of medians of patient satisfaction (VAS in $\mathrm{mm}$ ) for each question between ball and socket and $\mathrm{O} /$ ring attachments is presented in table 2. There was no significant difference between ball and socket and $\mathrm{O} /$ ring attachments regarding degree of satisfaction with socialization, degree of embarrassment, degree of satisfaction with handling of mandibular overdenture and ability to clean the mandibular prosthesis. Ball and socket attachment recorded significant higher patient satisfaction regarding retention $(\mathrm{p}=.027)$ and stability $(\mathrm{p}=.001)$ of mandibular overdenture, satisfaction with speech $(\mathrm{p}=.040)$, satisfaction with chewing $(\mathrm{p}=.015)$, satisfaction with occlusion of the prosthesis $(\mathrm{p}=.042)$, and satisfaction with quality of bolus before swallowing $(\mathrm{p}=.031)$ than $\mathrm{O} /$ ring attachment.

\section{DISCUSSION}

In this study, crestal bone loss was measured after 6 and 12 months as it has been well documented in the literature that amount of the implant bone loss occurred in the first year after implant loading ${ }^{41}$. Moreover, patient satisfaction was measured after 6 months to avoid activation or replacement of retentive elements that might give due to the wear of the retentive element. This wear is usually of occur after 6 months of denture use $\mathrm{e}^{42-44}$, and its retentive elements were activated or replaced, this will introduce a variable that affect the retentive forces of the attachment, and consequently affect patient satisfaction. In this study cone beam computerized tomography was used to evaluate peri-implant crestal bone loss instead of the conventional periapical radiography as it provides more information about crestal bone loss that occur in the buccal and lingual surface of the implants in addition to mesial and distal surface. Moreover, it is easy to perform even with elevated floor of the mouth that may interfere with placement of film holder if periapical radiographs are used. Moreover, cone beam CT has no magnification or distortion. The use of CBCT in measuring bone resorption around implants was recommended by other investigators ${ }^{36,45}$.
The implant survival rate was $100 \%$ in both groups. The high survival rate in both groups could be attributed to the high bone density in the interforaminal area of the mandible which provides sufficient primary stability of the implants. Moreover, the delayed loading protocol utilized in this study decreased implant micromotion and minimizes overloading of the implants during the critical healing period after implant insertion ${ }^{46}$. The increased survival rate of the implants in this study concurred with the results of other studies $^{10,47}$ in which the authors reported $100 \%$ survival rate for single implants using the conventional loading protocols. In contrast, Coutinho et al. ${ }^{8}$ reported $88.9 \%$ survival rate for single implants retaining a mandibular overdenture with $\mathrm{O} /$ ring attachment. This reduced survival rate could be attributed to the immediate loading protocol utilized by Coutinho and associates which may result in increased implant failures.

Two patients in the ball and socket group had denture fractures at midline opposite to the attachment which were repaired by metal reinforcement skeleton and no denture fractures occurred in the O-ring attachment group. The midline denture fractures were reported as the most frequent complication associated with single implant overdentures ${ }^{12,13}$. The denture fractures are located in the area of the attachment due to inadequate thickness of acrylic resin around the attachments. The increased denture fracture in the ball and socket group may be due to the fact that metal socket directly contacts the ball without intervening spaces. This creates a fulcrum when the patient exerted occlusal forces on posterior teeth during mastication and the denture rotates around this fulcrum. This may create crack initiation and propagation in the thin area of the acrylic resin around the ball and socket attachment with subsequently denture fracture ${ }^{48,49}$. The absence of denture fracture in the $\mathrm{O} /$ ring group could be attributed to the space present between the metal housing and the ball attachment which allow 
the dentures to settle toward the mucosa during mastication rather than forming a fulcrum.

The mean crestal bone resorption after one year was $1.15 \pm .36 \mathrm{~mm}$ and $.86 \pm .23$ for ball and socket and $\mathrm{O} /$ ring attachments respectively. These values are located within the normal limit of crestal bone loss reported in the literature that locator do during the first year ${ }^{41}$. However, Cordioli et al. reported $1.42 \pm 0.56 \mathrm{~mm}$ crestal bone loss for single implant overdentures with $\mathrm{O} /$ ring attachment after 60 months. The difference in the results would be attributed to the different evaluation periods and different techniques used for evaluation of crestal bone loss. Crestal bone loss significantly increased from 6 months to 12 months. This unavoidable time dependent bone loss could be attributed to bone response to healing process and loading. Similarly, Coutinho et al. ${ }^{8}$ reported a progressive marginal bone loss from baseline to all subsequent follow-ups for single implant retaining mandibular overdentures.

Ball and socket attachment recorded significant higher crestal bone loss than O-ring attachment. The increased peri-implant bone resorption with ball and socket attachments may be due to ball attachments absorbed most of the applied stresses as there is no space between the ball and the sockets as stated previously, thus a fulcrum was created over the ball and the denture rotates around the ball during mastication. This will transfer more stresses to the implant and may be responsible for increasing bone loss. Moreover, ball and socket attachment enhance bracing and increase stability by preventing lateral movement of the denture, therefore a lever arm is created which enhance stress concentration in the bone surrounding the implant ${ }^{50}$. In addition, the increased modulus of elasticity of the metal socket could contribute to the increased stresses on the ball abutments and the implants.

In contrast, $\mathrm{O} /$ ring attachment has a space present between the metal housing and the ball attachment which allow the dentures to settle toward the mucosa during mastication rather than forming a fulcrum as stated previous, consequently the stresses transmitted to the ball abutments are reduced. Moreover, O/ring attachment is totally resilient as it provides a wide range of movement, and allows denture movement in six different directions ${ }^{51}$. In addition, the reduced elastic modulus of the O/ring attachments reduced stresses transmitted to the ball abutment, and enhance loading of the residual ridge mucosa ${ }^{23} . \mathrm{O} /$ rings also provide vertical and rotational resiliency (totally stress breaking action), and transmitting reduced force to implant components ${ }^{23}$. Klemetti et $\mathrm{al}^{52}$ added that $\mathrm{O} /$ ring incorporated into the denture base can reduce shock, pressure and torque on the implants. The reduced stresses to the implants are associated with reduced crestal bone loss.

Ball and socket attachment recorded significant higher patient satisfaction regarding retention and stability of mandibular overdenture than O/ring attachment. The increased retention and stability with ball and socket attachment could be attributed to the design of the ball and socket which consisted of platinized gold socket that contact the ball without space inter-between. The lateral flanges of the socket contact the ball firmly thus provide excellent retention and stability without lateral (side to side) movement. The reduced patient satisfaction with retention and stability of $\mathrm{O} /$ ring attachment may be due to the high freedom of rotation and vertical resiliency provided by this type of attachment which reduces the retentive capacity. In line with this explanation, Chen et al. ${ }^{53}$ reported that, the least retentive components $(\mathrm{O} /$ ring) offer greater rotation than the most retentive components (ERA) for single attachments. The reduced retention and stability of the $\mathrm{O} /$ ring attachment could be attributed to the wear, deformation of the O-ring rubber matrix ${ }^{54}$. With our findings, Scherer et al. ${ }^{55}$ found that ball attachment produced the highest levels of retention and stability than O-Ring attachment. 
Ball and socket attachment recorded significant higher patient satisfaction regarding speech and occlusion of the mandibular overdenture than $\mathrm{O} /$ ring attachment. The increased retention and stability of ball and socket attachments provide stable occlusal plane, and limits wide movement of the dentures during the speech. In contrast, the freedom of denture movement provided by O-ring attachment during speech may enhance movement of the distal extensions of the dentures during speech and may alter the occlusal relation ${ }^{56}$. This could be responsible for reduced patient satisfaction with the speech and occlusion when using O-ring attachments. The reduced patient satisfaction with speech when using $\mathrm{O} /$ ring attachments for single implant overdenture was in line with the finding of another study ${ }^{10}$ in which the authors reported also overall decrease in patient satisfaction with overdentures after 5 years compared to baseline.

Ball and socket attachment recorded significant higher patient satisfaction regarding chewing and quality of bolus than O/ring attachment. Again, the increased retention and stability with ball and socket provides a stable occlusal plane, thus enhance adequate chewing and transmit masticatory forces vertical to the implants. This will increase the ability to grind the food during mastication and the denture has support from the implant. In contrast O-ring attachment provides more denture movement during mastication and the denture is totally supported by the mucosa. The increased patient satisfaction with chewing when ball and socket attachment was used agreed with the results of another study ${ }^{57}$ in which the authors found that ball and socket attachment achieved a high muscle activity. The increased chewing ability with ball and socket could be responsible for producing a bolus of food with high quality.

The increased patient satisfaction with Ball and socket for single implant overdenture was in agreement with another study ${ }^{58}$ that reported significant increase in patients' subjective satisfaction and a significant decrease in complaints after 1.5 year when symphyseal implant was used for anchorage of the mandibular complete denture with ball and socket attachment. The decreased patient satisfaction with O-ring attachment in this study was reported compared to ball and socket attachment. However, in other studies ${ }^{5,59}$, O-ring attachment showed significant improvement in patient perceived outcomes (patient satisfaction and oral health-related quality of life) compared to conventional dentures.

\section{CONCLUSION}

Within the limitation of short-term randomized trial, $\mathrm{O} /$ ring attachment is recommended than ball and socket attachment for single implant mandibular overdentures in term of peri-implant bone preservation. However, ball and socket attachment were associated with significant higher patient satisfaction than $\mathrm{O} /$ ring attachment.

\section{REFERENCES}

1. Grover M, Vaidyanathan AK, Veeravalli PT. OHRQoL, masticatory performance and crestal bone loss with singleimplant, magnet-retained mandibular overdentures with conventional and shortened dental arch. Clin Oral Implants Res. 2014;25:580-6.

2. Feine JS, Carlsson GE, Awad MA, Chehade A, Duncan WJ, Gizani S et al. The McGill Consensus Statement on Overdentures. Montreal, Quebec, Canada. May 24-25, 2002. Int J Prosthodont. 2002;15:413-4.

3. Thomason JM, Feine J, Exley C, Moynihan P, Muller F, Naert I et al. Mandibular two implant-supported overdentures as the first choice standard of care for edentulous patients--the York Consensus Statement. Br Dent J. 2009;207:185-6.

4. Alsabeeha N, Atieh M, Swain MV, Payne AG. Attachment systems for mandibular single-implant overdentures: an in vitro retention force investigation on different designs. Int J Prosthodont. 2010;23:160-6

5. Nogueira TE, Aguiar FMO, de Barcelos BA, Leles CR A 2-year prospective study of single-implant mandibular overdentures: Patient-reported outcomes and prosthodontic events. Clin Oral Implants Res. 2018;29:541-50. 
6. Paleari AG, Oliveira Junior NM, Marin DOM, Rodriguez LS, Arioli Filho JN, Pero AC et al. One-year prospective clinical study comparing patient satisfaction and masticatory performance of mandibular overdentures supported by one versus two implants. J Appl Oral Sci. 2018;26:e20160628.

7. Fu L, Liu G, Wu X, Zhu Z, Sun H, Xia H. Patient-reported outcome measures of edentulous patients restored with single-implant mandibular overdentures: A systematic review. J Oral Rehabil. 2021;48:81-94.

8. Coutinho PC, Nogueira TE, Leles CR. Single-implant mandibular overdentures: Clinical, radiographic, and patient-reported outcomes after a 5-year follow-up. J Prosthet Dent. 2021.

9. Pinheiro MA, do Amaral CF, Meira IA, Carletti TM, Camara-Souza MB, Souza CSV et al. Single implant overdenture reinforced with a metallic framework: A 2-year clinical follow-up. Spec Care Dentist. 2021.

10. Cordioli G, Majzoub Z, Castagna S. Mandibular overdentures anchored to single implants: a five-year prospective study. J Prosthet Dent. 1997;78:159-65.

11. Padmanabhan H, Kumar SM, Kumar VA. Single Implant Retained Overdenture Treatment Protocol: A Systematic Review and Meta-Analysis. J Prosthodont. 2020;29:287-97.

12. Passia N, Wolfart S, Kern M. Six-year clinical outcome of single implant-retained mandibular overdentures--a pilot study. Clin Oral Implants Res. 2015;26:1191-4.

13. Gonda T, Maeda Y, Walton JN, MacEntee MI. Fracture incidence in mandibular overdentures retained by one or two implants. J Prosthet Dent. 2010;103:178-81.

14. Liu J, Pan S, Dong J, Mo Z, Fan Y, Feng H. Influence of implant number on the biomechanical behaviour of mandibular implant-retained/supported overdentures: a three-dimensional finite element analysis. J Dent. 2013;41:241-9.

15. Mahoorkar S, Bhat S, Kant R. Single implant supported mandibular overdenture: A literature review. J Indian Prosthodont Soc. 2016;16:75-82.

16. Petropoulos VC, Smith W. Maximum dislodging forces of implant overdenture stud attachments. Int J Oral Maxillofac Implants. 2002;17:526-35.

17. Sato H, Kobayashi T, Nomura T, Tanabe N, Takafuji K, Kihara $\mathrm{H}$ et al. Oral mucosa pressure caused by mandibular implant overdenture with different types of attachments. Journal of prosthodontic research. 2020;64:145-51.
18. Alsabeeha NH, Payne AG, De Silva RK, Thomson WM. Mandibular single-implant overdentures: preliminary results of a randomised-control trial on early loading with different implant diameters and attachment systems. Clin Oral Implants Res. 2011;22:330-7.

19. Chung KH, Chung CY, Cagna DR, Cronin RJ, Jr. Retention characteristics of attachment systems for implant overdentures. J Prosthodont. 2004;13:221-6.

20. Mendez. A, Guerra L. Implant Overdentures In: Block MS, Kent JN: Endosseous Implants for Maxillofacial Reconstruction. Philadelphia: WB Sounders Co., . 1995:158-77.

21. Winkler S, Piermatti J, Rothman A, Siamos. G. An overview of the o-ring implant overdenture attachment: clinical reports. J Oral Implantol. 2002;28:82-6.

22. Pisani MX, Presotto AGC, Mesquita MF, Barao VAR, Kemmoku DT, Del Bel Cury AA. Biomechanical behavior of 2-implant- and single-implant-retained mandibular overdentures with conventional or mini implants. J Prosthet Dent. 2018;120:421-30.

23. Gibreel M, Sameh A, Hegazy S, Narhi TO, Vallittu PK, Perea-Lowery L. Effect of specific retention biomaterials for ball attachment on the biomechanical response of single implant-supported overdenture: A finite element analysis. J Mech Behav Biomed Mater. 2021;122:104653.

24. Tokuhisa M, Matsushita Y, Koyano K. In vitro study of a mandibular implant overdenture retained with ball, magnet, or bar attachments: comparison of load transfer and denture stability. Int J Prosthodont. 2003;16:128-34.

25. Maeda Y, Horisaka M, Yagi K. Biomechanical rationale for a single implant-retained mandibular overdenture: an in vitro study. Clin Oral Implants Res. 2008;19:271-5.

26. ELsyad M, Elgamal M, Askar O, Al-Tonbary G. Patient satisfaction and oral health-related quality of life (OHRQoL) of conventional denture, fixed prosthesis and milled bar overdenture for All-on-4 implant rehabilitation. A crossover study. Clin Oral Implants Res. 2019; 30:1107-17.

27. Elsyad MA. Patient satisfaction and prosthetic aspects with mini-implants retained mandibular overdentures. A 5-year prospective study. Clin Oral Implants Res. 2016;27:926-33.

28. De Grandmont P, Feine J, Tache R, Boudrias P, Donohue $\mathrm{W}$, Tanguay $\mathrm{R}$ et al. Within-subject comparisons of implant-supported mandibular prostheses: psychometric evaluation. J Dent Res. 1994;73:1096-104. 
29. Srinivasan M, Makarov NA, Herrmann FR, Muller F. Implant survival in 1- versus 2-implant mandibular overdentures: a systematic review and meta-analysis. Clin Oral Implants Res. 2014

30. Kronstrom M, Davis B, Loney R, Gerrow J, Hollender L. A prospective randomized study on the immediate loading of mandibular overdentures supported by one or two implants; a 3 year follow-up report. Clin Implant Dent Relat Res. 2014;16:323-9.

31. Nogueira TE, Schimmel M, Leles CR. Changes in masticatory performance of edentulous patients treated with single-implant mandibular overdentures and conventional complete dentures. J Oral Rehabil. 2019;46:268-73.

32. Bryant SR, Walton JN, MacEntee MI. A 5-year randomized trial to compare 1 or 2 implants for implant overdentures. J Dent Res. 2015;94:36-43.

33. Kronstrom M, Davis B, Loney R, Gerrow J, Hollender L. Satisfaction and Clinical Outcomes Among Patients with Immediately Loaded Mandibular Overdentures Supported by One or Two Dental Implants: Results of a 5-Year Prospective Randomized Clinical Trial. Int J Oral Maxillofac Implants. 2017;32:128-36.

34. Cheng T, Sun G, Huo J, He X, Wang Y, Ren YF. Patient satisfaction and masticatory efficiency of single implantretained mandibular overdentures using the stud and magnetic attachments. J Dent. 2012;40:1018-23.

35. Elsyad MA, Al-Mahdy YF, Fouad MM. Marginal bone loss adjacent to conventional and immediate loaded two implants supporting a ball-retained mandibular overdenture: a 3-year randomized clinical trial. Clin Oral Implants Res. 2012;23:496-503.

36. Elsyad MA, Khirallah AS. Circumferential bone loss around splinted and nonsplinted immediately loaded implants retaining mandibular overdentures: A randomized controlled clinical trial using cone beam computed tomography. J Prosthet Dent. 2016;116 741-8

37. Kim JH, Abdala-Junior R, Munhoz L, Cortes ARG, Watanabe PCA, Costa $\mathrm{C}$ et al. Comparison between different cone-beam computed tomography devices in the detection of mechanically simulated peri-implant bone defects. Imaging Sci Dent. 2020;50:133-9.

38. de Albuquerque Junior RF, Lund JP, Tang L, Larivee J, de Grandmont P, Gauthier G et al. Within-subject comparison of maxillary long-bar implant-retained prostheses with and without palatal coverage: patient-based outcomes. Clin Oral Implants Res. 2000;11:555-65.
39. Tang L, Lund JP, Tache R, Clokie CM, Feine JS. A withinsubject comparison of mandibular long-bar and hybrid implant-supported prostheses: psychometric evaluation and patient preference. J Dent Res. 1997;76:1675-83.

40. ELsyad MA. Prosthetic aspects and patient satisfaction with resilient liner and clip attachments for bar- and implant-retained mandibular overdentures: a 3-year randomized clinical study. Int J Prosthodont. 2012; $25: 148-56$

41. Albrektsson T, Zarb G, Worthington P, Eriksson AR. The long-term efficacy of currently used dental implants: a review and proposed criteria of success. Int $\mathrm{J}$ Oral Maxillofac Implants. 1986;1:11-25.

42. ELsyad MA, Emera RM, Ashmawy TM. Effect of Distal Implant Inclination on Dislodging Forces of Different Locator Attachments Used for Mandibular Overdentures: An In Vitro Study. J Prosthodont. 2019;28:e666-e74.

43. ELsyad MA, Emera RM, Ashmawy TM. Effect of Different Bar Designs on Axial and Nonaxial Retention Forces of Implant-Retained Maxillary Overdentures: An In Vitro Study. Int J Oral Maxillofac Implants. 2019;34:31-8.

44. ELsyad MA, Emera RM, Ibrahim AM. Effect of Labial Implant Inclination on the Retention and Stability of Different Resilient Stud Attachments for Mandibular Implant Overdentures: An In vitro Study. Int J Oral Maxillofac Implants. 2019;34:381-9.

45. Razavi T, Palmer RM, Davies J, Wilson R, Palmer PJ. Accuracy of measuring the cortical bone thickness adjacent to dental implants using cone beam computed tomography. Clin Oral Implants Res. 2010;21:718-25.

46. Brunski JB. In vivo bone response to biomechanical loading at the bone/dental-implant interface. Adv Dent Res. 1999;13:99-119.

47. Alqutaibi AY, Kaddah AF, Farouk M. Randomized study on the effect of single-implant versus two-implant retained overdentures on implant loss and muscle activity: a 12-month follow-up report. Int J Oral Maxillofac Surg. 2017; 46:789-97.

48. ELsyad MA, Errabti HM, Mustafa AZ. Mandibular Denture Base Deformation with Locator and Ball Attachments of Implant-Retained Overdentures. J Prosthodont. 2016;25:656-64.

49. ELsyad MA, Fathe Mahanna F, Samir Khirallah A, Ali Habib A. Clinical denture base deformation with different 
attachments used to stabilize implant overdentures: A crossover study. Clin Oral Implants Res. 2019.

50. Ozan O, Ramoglu S. Effect of Implant Height Differences on Different Attachment Types and Peri-Implant Bone in Mandibular Two-Implant Overdentures: 3D Finite Element Study. J Oral Implantol. 2015;41:e50-9.

51. Misch CE. Treatment Options for Mandibular Implant Overdentures in: Misch CE, Bidez MW, Judy KWM et al, eds Dental implant prosthetics. 3nd ed St Louis: Mosby. 2005:218-35.

52. Klemetti E, Chehade A, Takanashi Y, Feine JS. Twoimplant mandibular overdentures: simple to fabricate and easy to wear. J Can Dent Assoc. 2003;69:29-33.

53. Chen IC, Brudvik JS, Mancl LA, Rubenstein JE, Chitswe K, Raigrodski AJ. Freedom of rotation of selected overdenture attachments: an in vitro study. J Prosthet Dent. 2011;106:78-86.

54. Choi JW, Bae JH, Jeong CM, Huh JB. Retention and wear behaviors of two implant overdenture stud-type attachments at different implant angulations. J Prosthet Dent. 2017; 117:628-35.
55. Scherer MD, McGlumphy EA, Seghi RR, Campagni WV. Comparison of retention and stability of two implantretained overdentures based on implant location. J Prosthet Dent. 2014;112:515-21.

56. Misch C. Rationale for dental implants. In: Misch CE (ed). Contemporary Implant Dentistry, ed 3. St Louis: . Mosby. 2008:3-25.

57. ELsyad MA, Ibrahim AE, Nawar NHH, Belal TM. Electromyographic Connectivity of Masseter Muscle with Different Retentive Attachments for Implant Overdentures in Patients with Atrophied Mandibular Ridges: A Crossover Study. Int J Oral Maxillofac Implants. 2019;34:1213-22.

58. Krennmair G, Ulm C. The symphyseal single-tooth implant for anchorage of a mandibular complete denture in geriatric patients: a clinical report. Int J Oral Maxillofac Implants. 2001;16:98-104.

59. Nogueira TE, Aguiar FMO, Esfandiari S, Leles CR. Effectiveness of immediately loaded single-implant mandibular overdentures versus mandibular complete dentures: A 1-year follow-up of a randomized clinical trial. J Dent. 2018;77:43-50. 